\title{
At-Turats
}

Jurnal Pemikiran Pendidikan Islam

journal homepage: http://jurnaliainpontianak.or.id/index.php/atturats

\section{Rancangan Pembelajaran Fiqih dalam Konsep Kebijakan Adiwiyata Di SMP Bhakti Pertiwi Probolinggo}

\author{
Chusnul Muali ${ }^{\mathrm{a}, *}$, Ayu Megawati ${ }^{\mathrm{b}}$ \\ ${ }^{a}$ Universitas Nurul Jadid Probolinggo, Jawa Timur, Indonesia \\ yayahdaddy@gmail.com \\ ${ }^{b}$ Universitas Nurul Jadid, Probolinggo, Jawa Timur, Indonesia \\ megawatiayu7@gmail.com
}

\begin{abstract}
Every individual has an important role in maintaining and caring for the environment, environmental damage is not only an obligation of the government but all communities and educational institutions also take responsibility, so the government has issued an Adiwiyata program policy in schools. The aim of the researchers was to find out how far the achievement of the Adiwiyata level and the integration of Adiwiyata in figh learning at SMP Bhakti Pertiwi, researchers used a qualitative approach to interpret phenomena that occur and are carried out involving various existing research methods, namely interviews and observations. The article discusses the implementation of fiqh learning in the Adiwiyata program of the Bhakti Pertiwi Middle School based on the results of the researchers concluded that the character of students in environmental education has been very good with the integration of the Adiwiyata program in figh learning students can practice directly how to use water and electricity.
\end{abstract}

Keywords: Adiwiyata, fikih, Environmental care 


\section{PENDAHULUAN}

Political and Economic Risk Consultant (PERC), menyebutkan bahwa Indonesia berada diurutan paling buncit dalam urusan kualitas pendidikan diantara negara-negara Asia. Hal ini disebabkan rendahnya kualitas sumber daya masyarakat Indonesia.Senada dengan laporan The World Economic Forum Swedia di tahun 2000 yang meletakkan Indonesia di urutanke 37 dalam aspek kompetensi dan daya saing masyarakatnya.Pengembangan dan pembinaan dalam upaya peningkatan sumber daya manusia dapat dilakukan dengan berbagai cara, diantaranya adalah dengan proses pembelajaran di sekolah. Selaras dengan hasil penelitian yang dilakukan oleh (Al-anwari, 2016) yang dilakukanpada 2 (dua) sekolah yang telah sampai pada jenjang level adiwiyata yaitu SDN Tanjungsekar dan SDN Tulungrejo 4 Batu, menyebutkan bahwa sekolah menjadi acuan pendidikan untuk mengembangkan potensi siswa dan mengembangkan karakter siswa. (ZA, 2017) Namun kondisi dan lingkungan sekolah turut mewarnai kondisi belajar peserta didik. Hal senada disampaikan oleh Rismawati Tri dalam (Mukani, 2017) yang memaknai Adiwiyata sebagai tempat yang baik dan ideal, adiwiyata mendorong dan mencetak sekolahsekolah di Indonesia untuk melaksanakan pelestarian lingkungan hidup dan membangun sebuah cita-cita pembangunan berkelanjutan.

Hasil penelitian Badarudin dalam (Mukani, 2017) menyatakan bahwa terdapat perbedaan efektifitas keterampilan berpikir kreatif siswa yang diarahkan kepada karakteristik peduli dan cinta lingkungan.Penanaman karakter dalam pendidikan bertujuan agar peserta didik mempunyai kesadaran peduli lingkungan, Program Adwiyata sebagai program yang lahir dari kebijakan pemerintah, dilatarbelakangi keinginan pemerintah untuk menjadika suasana belajar yang kondusif, layak tinggal dan beberapa pertimbangan lain yang diarahkan kepada kepentingan belajar dan pelestarian lingkungan hidup.

Dengan adanya program Adiwiyata, menjadikan warga sekolah bertanggung jawab dan melindungi lingkungan hidup berdasarkan pengelolaan sekolah untuk mendukung pembangunan berkelanjutan, warga sekolah diharapkan dapat mengembangkannya dan memberikan contoh peduli lingkungan kepada masyarakat. (Mukani, 2017) Adiwiyata digunakan sebagai program pelestarian lingkungan hidup yang ditanamkan kepada warga sekolah, dilakukan guna membangun karakter manusia peduli lingkungan, mengajarkan untuk mencegah kerusakan lingkungan hidup, dan menjadikan tempat yang baik dan ideal, untuk membiasakannya dimulai dari hal terkecil seperti pembiasaan dalam keluarga, menjaga tatanan lingkungan yang bersih di sekolah, dan kegiatan-kegiatan lain yang mengarah kepada pelestarian lingkungan hidup.

Pendidikan memiliki kedudukan yang sangat penting didalam kegiatan pengajaran sebagai salah satu disiplin ilmu yang diajarkan di sekolah,(Hasibuan, 2016) Pendidikan Agama Islam sangat penting untuk diajarkan kepada warga sekolah agar peserta didik dapat meningkatkan keimaman, ketakwaan, dan berakhlak mulia.Pendidikan Agama Islam (PAI) memiliki empat mata pelajaran substansial, salah satumya adalah mata pelajaran Fiqih. Penanaman karakter peduli lingkungan dalam pendidikan bertujuan agar peserta didik memiliki pengetahuaan dan kesadaran bahwa setiap individu memililiki kesadaran peran penting dengan lingkungan sekitar dalam membentuk perubahan, membentuk karakter peduli lingkungan dapat diluaskan melalui beberapa program yang telah dibentuk khusus untuk membiasakan siswa berkarakter peduli terhadap lingkungannya, salah satu untuk membentuk karakter peduli lingkungan yaitu melalui pembelajaran fiqih, pembelajaran fiqih merupakan ilmu yang mengkaji tentang hukum-hukum yang menyangkut tingkah laku manusia yang bersumber dari dalil-dalil.

Pendidikan Agama Islam disampaikan dengan mengikuti melalui tuntunanbahwasanya agama diajarkan kepada makhluk dengan visi untuk mencetak orang yang bertaqwa dan berahlak mulia kepada Allah SWT serta bertujuan untuk memperoleh oramg yang jujur, 
adil, sopan, saling menghargai, disiplin dan harmonis, baik personal ataupun sosial. (Siti Maesaroh, 2013)Pembelajaran Pendidikan Agama Islam juga sebagai mata pelajaran yang memiliki unsur keagamaan di dalamnya, merupakan suatu upaya konkrit yang dirancang guna membantu sekelompok orang dalam mengembangkan pandangan hidup, bagaimana orang menjalani hidup dan pandangan hidupnya.

Program Adiwiyata dalam bidang lingkungan hidup merupakan salah satu kebijakan yang menarik untuk diteliti. Kebijakan adiwiyata dikeluarkan oleh pemerintah akibat kerusakan lingkungan yang makin hari makin meningkan banyak dan beragam. (Muttaqin, 2017)

Penelitian ini dilakukan di salah satu sekolah di wilayah kabupaten Probolinggo yang telah menerapkan fungsinya sebagai sekolah adiwiyata, yaitu SMP Bhakti Pertiwi.Sebagai sekolah adiwiyata, SMP Bhakti Pertiwi mengimplementasikan "pesan" adiwiyata dalam setiap mata pelajaran, tak terkecuali mata pelajaran Fiqih.Dalam artikel ini, peneliti mengungkap penerapan rancangan pembelajaran untuk mata pelajaran Fikih pada sekolah yang telah menerapkan adiwiyata.

\section{KAJIAN TEORI}

\section{Rancangan pembelajaran fikih}

Pembelajaran sebagai aktivitas yang bernilai edukatif, mewarnai hubungan antara pendidik dan peserta didik. Interaksi yang bernilai edukatif dikarenakan aktivitas belajar yang dilakukan diarahkan untuk memperoleh target tertentu yang telah dirumuskan sebelum penmbelajaran dimulai. Guru dengan sadar melakukan kegiatan pengajarannya untuk memahamkan peserta didik.(Hasibuan, 2016)

Sebuah pembelajaran yang baik merupakan kegiatan belajar yang dilakukan dengan memilih strategi yang tepat dengan merumuskan tujuan yang dicapai. Selain itu keterlibatan murid secara aktif dalam pembelajaran merupakan kunci utama belajar.Tujuan pembelajaran mesti bersifat behavioralistik dan measurable yang artinya bahwa tujuan pembelajaran dapat memenuhi kebutuhan sikap serta perilaku peserta didik yang dapat diamatai dan diukur hingga memudahkan dalam mengartikan tercapainya tujuan pembelajaran. (Chusnul, 2016).

Pembelajaran fiqih diarahkan guna
mengantarkan siswa supaya mengetahui
hukum islam dan selalu taat mengerjakan
syariat islam secara sempurna. (Zaenudin,
2015) Mata pelajaran fikih adalah salah satu
mata pelajaran pendidikan islam diarahkan
untuk menyiajikan peserta didik dalam
mengenal, memahami dan menghayati
paling utama dalam ibadah sehari-hari, yang
menjadi dasar pedoman hidup melalui
kegiatan arahans, pengajaran, latihan,
penggunaan materi pengalaman dan
pembiasaan. Dengan demikian
pembelajaran fikih tidak hanya
mendengarkan apa yang dipaparkan oleh
pendidik saja tetapi siswa melalui aktifitas
bimbingan, latihan dan pembiasaan dalam
kegiatan pembelajaran.

Pembelajaran Fikih harus dimulai sejak dini. keberhasilan pendidikan fikih dapat dilihat dari kehidupan setiaphari, baik itu dalam lingkungan keluarga, sekolah, maupun masyarakat. Misalnya, dalam keluarga pembiasaan peserta didik dalam melaksanakan ibadah sholat secara individu dengan rutin. Sedangkan dalam komplek sekolah misalnya anak melaksanakan ibadah seperti shalat dan puasa dalam kehidupan setiaphari. Dalam (Sutrisno \& Siswanto, 2016) pembelajaran fikih, tidak hanya terjadi proses hubungan antara pendidik dan peserta didik didalam kelas. Namun pembelajaran dilaksanakan juga dengan berbagai interaksi, baik di lingkungan kelas maupun sekitar sebagai tempat untuk praktek yang menyangkut ibadah film dan lainnya yang mendukung dalam prosedur pembelajaran itu. Termasuk pula kejadian-kejadian social baik yang terjadi dimasa sekarang maupun masa lampau, yang bisa dijadikan cerminan dalam perbandungan dan penerapanhukum oleh peserta didik.Penggunaan media dalam pembelajaran merupakan fasilitas penunjang yang dapat me- 
ningkatkan efisiensi dan efektivitas keberhasilan pembelajaran.

(Syathori, 2013) Pembelajaran fikih di MTS/SMP bertujuan untuk membekali anak didik agar dapat:

a) Mengetahui pokok-pokok hukum Islam dalam mengatur ketentuan dan tata cara hubungan umat dengan sesama yang diatur dalam fikih muamalah

b) Melaksanakan dan juga mengamalkan ketentuan hukum-hukum Islam dengan benar dan melaksanakan ibadah kepada Allah dan ibadah social.

Pembelajaran isi kurikulum fikih di MTS/SMP merupajan kelanjutan dari kurikulum di MI, beberapa isi kurikulum merupakan perluasan dan pendalaman dari isi sebelumnya. Dalam hal ini pendidik diharapkan dapat membangun dan mengembangkan metode pembelajaran sesuai dengan standar kompetensi dan kompetensi dasar diarahkan untuk memberikan keterampilan dan keahlian bertahan hidup dalam kondisi yang penuh dengan berbagai perubahan,persaingan dan kerumitan dalam hidup.Pemilihan salah satu model pengembangan kurikulum akan berdampak pada perkembangan suatu peradaban. Selain itu, berkaitan dengan perubahan, pembaharuan, perbaikan dan pengembangan kurikulum, maka sangat dibutuhkan berbagai pihak dalam mewujudkan kurikulum yang yang tepat, serasi dan harmonis sehingga apa yang menjadi tujuan yang telah ditentukan dapat tercapai.(Muhamad Tisna Nugraha, 2016)

(NURHAYANI, 2017) Siswa tidak pernah lepas dengan dunia Fikih, yang dekat dengan aktivitas kehidupan mereka. Untuk itu dalam pembelajaran diperlukan metode yang sesuai dengan tingkat perkembangan peserta didik.Dengan demikian pemilihan metode yang tepat dan efektif sangat diperlukan bagi peserta didik agar pembelajaran berjalan dengan baik.

Menurut (Fahmi, 2015) berbagai metode pendidikan dan pembelajaran yang digunakan dalam berbagai pendekatan lain dapat digunakan juga dalam proses pendidikan dan pengajaran. Hal tersebut penting dalam memberi warna kepada proses pendidikan dan pembelajarannya, sehingga lebih menarik dan tidak membosankan dalam melaksanakan belajar mengajar. Adapaun macam-macam jenis metode pembelajaran anatara lain yaitu:

1) Metode ceramah suatu metode mengajar dengan menyampaikan informasi pengetahuan beberapa siswa

2) Metode tanya jawab salah satu cara mengajar yang dapat membantu kekurangan-kekurangan yang ada pada metode ceramah

3) Metode diskusi yaitu motode yang sangat erat memecahkan msalah (problem solving)

4) Metode demontrasi cara yang dipakai dalam pmbelajaran dengan mempertunjukkan sesuatu.

5) Metode resitasi yaitu metode pengajaran yang dipakai untuk menulis resume.

6) Metode sosio darama cara mengajar dengan jalan mendramatisasikan bentuk tingkah laku dalam hubungan sosial alam kehidupan sehari-hari

Dengan adanya metode pembelajaran maka suatu pembelajaran akan berjalan dengan efektif dan efesien juga akan mempermudah proses suatu pembelajaran.

2. Implementasi kebijakan Adiwiyata

Adiwiyata adalah suatu program yang bertujuan untuk menciptakan suasana yang baik bagi lembaga pendidikan untuk menjadi tempat penerima ilmu dan penyadaran bagi penghuni sekolah (guru, peserta didik, dan pekerja lainnya), untuk mendorong dalam menyelamatkan lingkungan dan pembangunan berkelanjutan yang dapat mengamalkan kelembagaan sekolah yang peduli dan berbudaya lingkungan berdasarkan norma kebersamaan, kejujuran, keadilan, serta kelestarian lingkungan hidup serta sumber daya alam. Guna menciptakan sekolah berwawasan lingkungan hidup. (Ramdani, 2006)

Untuk mewujudkan pengembangan kebijakan sekolah yang peduli dan berbudaya Lingkungan, maka membuat dan menetapkan kebijakan sekolah yang mendukung diluncurkannya kegiatan PLH 
oleh semua penduduk sekolah sesuai dengan komponen adiwiyata. .Implementasi kebijakan adiwiyata dilaksaaka berdasarkan memorandum bersama antara Mentri Negara dengan Mendiknas No 0142/U/1996 dan No.Kep 89/MenLH/5/1996; Kesepakatan Bersama KemenLH dengan Depdiknas KEP 7/MenLH/06/2005 dan No. 05/VI/KB/2005, tentang pembinaan dan pengembangan lingkungan hidup. ${ }^{1}$

Implementasi kebijakan sekolah peduli dan berbudaya lingkungan di SMP Bhakti Pertiwi 2009 masih melajar memahami tentang adiwiyata hingga samapai pada tahun 2011 medapat penghargaan tingkat kabupaten. Pada tahun 2013 medapat penghargaan tingkat provinsi dan tingkat nasional.Sampai sekarng pada tahun 2018 SMP Bhakti Pertiwi meraih Adiwiyata tingkat Nasional.

program Adiwiyata yang dilaksanakan pada lembaga-lembaga sekolah bermaksud buat mewujudkan sekolah yang peduli dan berbudaya lingkungan, sekolah yang bergelar Adiwiyata belum menjamin untuk mewujudkan pemahaman yang baik mengenai lingkungan, serta perilaku dan tindakan yang mencontohkan kepedulian lingkungan. (Rizky Dewi Iswari \& Jurusan, 2017)

Secara formal PLH menjadi salah satu alternatif yang rasional untuk memasukkan kedalam kurikulum. PLH menjdi salah satu faktor penting dalam keberhasilan pengelolaan lingkungan Hidup dan juga menjadi sarana penting guna menghasilkan SDM yang dapat melaksanakan prinsip pembangunan berkelanjutan. Adapun prinsip-prinsip yang dijalankan sesuai dengan program Adiwiyata sebagai berikut :(Landriany, 2014)

1) Edukatif : bersifat mendidik seluruh warga sekolah sifitas akademis bersifat mendidik semuanya wajib mejalankan program adiwiyata

${ }^{1}$ Kementrian Lingkungan hidup, 2012, Adiwiyata, (online: http;//www.menlh.go.id) diakses pada tanggal 12 Desember 2018
2) Partisipatif: berlaku untuk semuanya baik siswa maupun guru kemudian karyawan termasuk wali murid serta komite bahkan pengurus yayasan juga saling berpartisipasi

3) Berkelanjutan: program ini tidak hanya sampek karna sudah mendapakant penghargaan atau prestasi tapi dia sebuah prinsip yang sudah masuk terinternalisasi kegiatan siswadan didalam seluruh karyawan karena itu program ini terus berkelanjutan terlaksana betul dalam lingkungan sekolah.

Tujuan program Adiwiyata menurut (Lusiana Sri Sunarti, Isjoni 2017) untuk menghasikan peserta didik yang berkomitmen dalam upaya perlindungan dan pengelolaan lingkungan hidup melalui tata kelola sekolah yang baik, untuk membantu pembangunan berkelanjutan. Agar dapat tercapai diperlukan beberapa komponen yang mendukung pencapaian tujuan tersebut, maka ditetapkan 4 komponen program Adiwiyata yang ditetapkan menjadi satu kesatuan utuh dalam mencapai sekolah Adiwiyata, keempat komponen tersebut yaitu:

1. Kebijakan Berwawasan Lingkungan.

2. Kurikulum Berwawasan Lingkungan.

3. Kegiatan Lingkungan Berbasis Partisipatif.

4. Pengelolaan Sarana dan Prasarana Ramah Lingkungan.(Muttaqin, 2017)

Dalam mewujudkan lembaga yang peduli dan berbudaya lingkungan maka dibutuhkan beberapa kebijakan sekolah yang membantu untuk pelaksanaan kegiatan pendidikan lingkungan hidup bagi seluruh warga sekolah sesuai dengan prinsip dasar Program Adiwiyata yaitu partisipatif dan berkelanjutan. Pengembangan kebijakan sekolah tersebut antara lain:

1. Visi dan misi lembaga sekolah

2. Kebijakan suatu lembaga dalam mengembangkan PLH

3. Kebijakan peningkatan kapasitas SDM 
4. Kebijakan lemabaga sekolah dalam penghematan sumberdaya alam

5. Kebijakan sekolah yang mendukung guna menciptakan lingkungan sekolah yang bersih dan sehat

6. Kebijakan sekolah dalam mengalokasikan dan penggunaan dana terkait dengan lingkungan hidup.

Pendidikan Lingkungan Hidup dapat membantu dalam pembentukan karakter, khusunya karakter peduli lingkungan peserta didik di sekolah. Hal itu didasarkan pada tujuan dari Pendidikan Lingkungan Hidup. (Bahrudin, 2017) Secara umum sekolah Adiwiyata bertujuan untuk mewujudkan penduduk sekolah peduli dan berbudaya lingkungan dengan cara:

1) Menciptakan kondisi lebih baik bagi penghuni sekolah untuk menjadi tempat transer ilmu dan penyadaran bagi penghumi sekolah (guru, murid, dan staf-staf yang lain) dalam upaya plestrian lingkungan hidup.

2) Mendorong dan membantu sekolah ikut pemerintah dalam melestarikan lingkungan hidup dan pembanguna berkelanjutan demi generasi selanjutnya.

3) pihak sekolah ikut bertanggung jawab guna penyelamatan lingkungan hidup dan pembangunan berkelanjutan.

Tersangkut dengan permasalahan lingkungan yang semakin hari makin meningkat dan beragam maka sangat diperlukan adanya suatu pengelolaan agar lingkungan yang sudah mengalami kerendahan kualitas tersebut tidak menjadi semakin parah namun terjadi pencegahan yang lebih baik. (Ramdani, 2006) Manfaat program Adiwiyata diharapkan bagi setiap sekolah dapat menerapkan program tersebut kepada siswa, adapun manfaat program adiwiyata diantaranya:

1. Mengubah perilaku peserta didik guna melakukan budaya pelestarian lingkungan.

2. Mengurangi penggunaan sumber daya dan energi.

3. Dapat menghindari akibat dampak lingkungan yang ada dilingkungan sekolah

4. Meningkatkan pelaksanaan kegiatan operasional sekolah
5. Menjadikan tempat pembelajaran bagi generasi muda mengenai perlindungan dan penyelenggaraan lingkungan hidup yang baik dan benar.

6. Meningkatkan kondisi belajar mengajar lebih nyaman bagi penghuni sekolah.

Maka dengan adanya prinsip-prinsip Adiwiyata, kebijakan Adiwiyata serta tujuan Adiwiya maka program pendidikan lingkungan hidup akan terlaksana dan berjalan dengan baik disetiap lembagalembaga sekolah yang melaksanakan PLH.

3. Implementasi materi fikih dalam program Adiwiyata

Pendidikan lingkungan adalah salah satuupaya untuk memberikan pengetahuan lingkungan di kalangan pelajar sekolah. Hal ini ditujukan dengan asumsi bahwa jika pengetahuan tentang lingkungan meningkat, maka perilaku peduli lingkungan juga meningkat dan akan mengurangi kerusakan lingkungan di masa mendatang. Menurut (Mukani, 2017)Adiwiyata sebagai sekolah peduli lingkungan dan berbudaya lingkungan, hubungan pendiikan peduli lingkungan hidup dengan agama sangat erat yaitu dengan penumbuhan karakter cinta lingkungan yang didasari dengan dalil, sehingga dapat memantapkan peserta didik dalam melaksanakan upaya peningkatan karakter peduli lingkungan yang berkonsep keaktifan dan istiqomah siswa dalam melakukannya. Pembetukan karakter peduli lingkungan melalui pembelajran, khususnya dalam pembelajaran fikih karena pelajaran tersebut banyak tuntunan syari'at Islam yang berhubungan dengan manusia sehari-hari mulai dari pembelajaran tentang thaharah, shalat, puasa, mu'amalah dan lain-lain.

Menurut (Rizky Dewi Iswari\& Jurusan, 2017) Program Adiwiyata yang diaplikasikan dibeberapa sekolah bertujuan untuk menciptakan sekolah yang peduli dan berbudaya lingkungan bahwa sekolah yang bergelar Adiwiyata belum menjamin untuk mewujudkan pemahaman yang baik mengenai lingkungan, serta perilaku yang mencontohkan kepedulian lingkungan 
Seorang guru juga harus mampu mengondisikan peserta didiknya agar tidak "semeraut" dalam melaksanakan kegiatan seperti halnya ketika dalam proses belajar mengajar atau ketika dalam kegiatankegiatan lainnya. (Hasan Baharun, 2018) Pendidikan agama Islam mencakup 4 mata pelajaran yang ditanamkan kepada peserta didik diantaranya : 1) Qur'an hadhis 2) Aqidah akhlak 3) sejarah kebudayaan Islam 4) fikih, sebagai mata pelajaran PAI mempunyai peran penting dalam menyadarkan nilai-nilai ajaran Islam kepada peserta didik, implementasi dari salah satu matapelajaran PAI agar peserta didik dapat mengetahui, memahi, meyakini dan mengamalkan ajaran agama Islam. Di dalam kurikulum matapelajaran PAI fiqih diarahakan untuk menyiapakan peserta didik mengenal, memahami dan mengamalkan hukum Islam.

Dalam mata pelajaran fikih terdapat materi yang mencakup aspek tentang thahara (bersesuci) didalam syariat Islam orang yang hendak melaksanakan ibadah sholat dianjurkan untuk melaksakan wudhu' terlebih dahulu untuk membersihkan kotoran-kotoran najis. Cara menggunakan air ketika berwudhu' tidak boleh berlebihan, dalam program Adiwiyata peserta didik ditanamkan karakter peduli lingkungan hemat air dan energi listrik.Pentingnya mata pelajaran fiqih disini untuk menanamkan hukum-hukum dalam agama Islam.

Fikih merupakan sistem norma yang mengatur hubungan hambanya dengan Allah dan dengan makhluk lainnya. Aspek fikih menegaskan pada kemampuan cara pelaksanaan ibadah dan muamalah yang benar dan baik. Sehingga mempermudah siswa dalam menerapkannya pada kehidupan sehari-hari. (NURHAYANI, 2017) Hukum yang ada didalam fiqih terdiri dari hukum wajib, sunah, makruh dan haram selain itu terdapat pula yang lain seperti sah, batal, benar, salah, berdosa dan berpahala. Seperti terkait dengan materi thoharah tentang najis yang terbagi menjadi 3 macam: 1) najis mughalladhah 2) najis mukhaffafah
3) najis mutawassithah. Dari pembahasan macam-macam najis tersebut peserta didik akan mengetahui cara-cara mensucikan najis dan hukum-hukum najis.

\section{METODE PENELITIAN}

Penelitian ini penggunakan pendekatan kualitatif karena data-data yang yang diperoleh berupa data deskriptif, dalam bentuk pernyataan-pernyataan atau katakata yang berasal dari sumber data agar mudah dipahami, terkait dengan pelaksanaan program adiwiyata pada pembelajaran fiqih melalui pengamatan lapangan di SMP Bhati Pertiwi. Sumber data penelitian ini yaitu melibatkan Guru PAI, Devisi adiwiyata SMP Bhakti Pertiwi dan Siswa kelas VII sedangkan pengumpulan data menggunakan teknik observasi, wawancara dan dokumentasi.

1. Wawancara adalah sebuah proses perolehan keterangan untuk tujuan penelitian dengan cara Tanya jawab sambil tatap muka antara pewawancara dengan orang yang diwawancarai.

2. Observasi yaitu tekhnik pengumpulan data dengan cara mengamati langsung pada objek penelitian dan mencatat beberapa hal penting yang berhubungan dengan penelitian.

3. Dokumentasi Penulis mengumpulkan informasi atau dokumen melalui dengan menggunaka camera handphone, buku catatan kecil dan alat pendukung lainnya.Dalam penelitian ini, penulis juga menggunakan internet sebagai tambahan informasi.

\section{HASIL DAN PEMBAHASAN}

1. Pencapaian program adiwiyata SMP Bhakti Pertiwi

Perolehan Adiwiyata SMP Bhakti Pertiwi, Pada tahun 2009 SMP Bhakti Pertiwi Probolinggo masih melajar memahami program Adiwita selanjutnya pada tahun 2011 SMP Bhakti Pertiwi mendapat penghargaan Adiwiyat tingkat Kabupaten, penghargaan diberikan oleh bupati/walikota,berlanjut pada tahun 2013 
mendapat penghargaan Adiwiyata tingkat Propinsi penghargaan diberikan oleh Gubernur, hal ini dengan kegigihan semua pihak sekolah hingga meraih Adiwiyata tingkat Nasional pada tahun yang sama yaitu 2013, penghargaan diberikan oleh menteri Lingkungan hidup dan kehutanan, untuk menjadi adiwiyata mandiri SMP Bhakti Pertiwi harus mempunyai sepuluh sekolah binaan, pada tahun 2018 ada 3 sekolah di Kabupaten Probolinggo yang meraih penghargaan Adiwiyata salah satunya SMP Bhakti Pertiwi resmi meraih Adiwiyata tingkat mandiri. ${ }^{2}$

Adapun filosofi dasar SMP Bhakti Pertiwi yang masuk dalam visi dan misi SMP Bhakti Pertiwi yaitu terwujudnya siswa yang bertaqwa, memiliki prestasi akademis yang tinggi, memiliki kecakapan hidup dan berwawasan Lingkungan, tentu dalam pelaksanaannya sangat penting sebagai peran peseta didik, terutama guru-guru dan stekholder. Implementasi program lingkungan hidup terintegrasi didalam seluruh mata pelajaran dan juga muatan lokal, dalam hal ini muatan lokal ada pembelajaran secara khusus pedidikan lingkungan hidup demikian juga progrm pengembangan diri ekstra kulikuler yang wajib maupun yang pilihan semuanya terintegrasi dalam pendidikan lingkungan hidup atau Adiwiyata, keberhasilan ini tentu tidak lepas dari anggaran yang dialokasikan oleh SMP Bhakti Pertiwi, adapun rekap anggaran sekolah sebagai contoh tahun 2017 dan 2018 itu mencapai $32 \%$.

Dijelaskan pula bagaimana perolehan capaian program adiwiyata SMP Bhakti Pertiwi yang pertama pengurangan jumlah himpunan sampah $150 \mathrm{KG}$ perhari sejak berjalannya program adiwiyata sampah menjadi $23 \mathrm{KG}$ perhari, kedua pemanfaatan daur ulang sampah, ada beberapa program yang bisa dimanfaatkan bagaimana mendaur ulang sampah 1) Sampah ekonimis kerjasa dengan berpajak pihak ke 3 untuk menjual sampah plastik. 2) Pemanfaatan botol air mineral yang dapat digunakan sebagai polibek dan pembibitan tanaman hias 3) Pemanfaatan kertas bekas layak pakai digunakan untuk mendaur ulang 4). Budidaya ikandi dalam ember.kemudian capaian luar biasa Adiwiyata yg diperoleh mendaur ulang sampah yaitu pembuatan kompos dari sampah organik dan pupuk kompos yang cair kemudian pencapaian melakukan konservasi energi: 1) menggunakan pemasangan stiker hemat. 2) elektronik hemat listrik 3) menggunakan instalasi listrik yang hemat energi 4) pemanfaatan bekas cuci tangan wastafel untuk pemeliharaan taman sekolah, 5) pemnfaatan bekas air wudhu' pemeliharaan untuk kolam ikan dan tanaman.

Adiwiyata memiliki komponen, masingmasing komponen memiliki tantangan yang berbeda.Adiwiyata yang diurusi tidak hanya RPP dewan guru saja namun dalam pembiasaan seluruh sivitas sekolah sampai makanan dan kebijakan kepsek semuanya diurusi. Sejak tahun 2003 berdirinya SMP Bhakti Pertiwi menyediakan makan siang untuk semua warga sekolah, Adiwiyata bergerakdibagian menjaga kualitas makanan yang baik dan sehat dengan standart kesehatan makan di SMP Bhakti Pertiwi bekerjasama dengan instansi kesehatan (puskesmas paiton). ${ }^{3}$

2. Implementasi program adiwiwyata pada materi fikih

Semua mata pelajaran yang ditranser kepada warga sekolah SMP Bhakti Pertiwi Probolinggo sudah terintegrasi dengan Adiwiyata atau dapat disebut terintegrasi dengan Pendidikan Lingkungan Hidup. Semua mata pelajaran dapat diintegrasikan dengan lingkungan hidup seperti bahasa Indonesia, kewarganegaraan, matematika, kesenian dan pendidikan yang berbasis Islam juga bisa diintegrasikan dengan pendidikan lingkungan hidup seperti al- 
Qur'an Hadits, Akhlak, sejarah kebudayaan Islam dan fikih.

Salah satu mata pelajaran yang terintegrasi dengan Adiwiyata yaitu materi fikih karena membahas hal-hal mengenai: Hubungan manusia dengan allah SWT, Hubungan manusia dengan alam (selain manusia) dan lingkungan. Pembelajaran pendidikan agama Islam mata pelajaran fiqih terkait dengan program Adiwiyata yang diterapkan pada SMP Bhakti Pertiwi berhubungan dengan hal-hal mengenai hubungan manusia dengan alam, peserta didik ditanamkan dan diarahkan untuk hidup bersih menjaga kelestarian lingkungan sekolah, membuang sampah pada tempatnya melaksanakan piket kelas atau membersihkan sekolah. Hubungan manusia dengan Allah SWT, dalam peraturan sekolah peserta didik harus melepas sepatu ketika masuk kelas hal ini untuk menjaga kesucian atau kebersihan agar tidak menimbulkan najis-najis dalam suasana kelas dan terkait penggunaan air peserta didik diajarkan untuk tidak menggunakan air berlebih-lebihan ketika berwudhu' atau pada saat membersihkan najis dan mensucikannya.

Menurut Abdul wahab guru PAI SMP Bhakti pertiwi mengartikan Adiwiyata sebagai penghematan atau menjaga kebersihan dalam artian hemat menggunakan listrik yang ada di sekolah seperti menggunakan air ketika berwudhu' dan menjaga kebersihan lingkungan sekolah seperti yang tercantum dalam hadis Nabi kebersihan sebagian dari iman, semua mata pelajaran terintgrasi dalam program adiwiyata, adiwiyata mempunyai pembelajaran muatan lokal artinya pembelajaran khusus jadi enak buat siswa untuk menanamkan karakter peduli lingkungan, kaitannya Adiwiyata dengan fikih yaitu mengenai penggunaan air bagaimana cara mensucikan dengan air agar hemat tidak berlebihan dan Alhamdulillah
SMP Bhakti pertiwi menjadi sekolah Adiwiyata mandiri pada tahun sekarang. ${ }^{4}$

Halsenada disamapaikan masrus sivitas adiwiyata, mengartikan Adiwiyata sebagai sekolah peduli dan berbudaya lingkungan, yang perlu dipahami diposisi adiwiyata yaitu menjaga lingkungan.Dimana kita tidak boleh berlebihan menggunakan air, harus hemat air jangan sampai ibadah kita tidak diterima karena air untuk bersesuci malah dibuang-buang secara berlebihan.Bersesuci dengan air secukupnya atau tidak berlebihan hal ini yang terkait dengan pembelajaran fikih thahara.

Tidak jauh berbeda dengan yang dikemukkan oleh Dira salah satu murid kelas 7B program Adiwiyata memang berjalan dengan baik namun jika dalam materi fikih yang diterapkan tentang kebersihan sebagian dari iman dan cara menggunakan air tidak berlebih-lebihan yang disampaikan oleh guru PAI karena untuk pembelajaran PLH sudah ada mata pelajaran khusus untuk diajarkana kepada peserta didik. ${ }^{5}$

Dari hasil diatas dapat disimpulkan bahwa adiwiyata sebagai sekolah peduli dan berbudaya lingkungan atau penghematan. Program Adiwiyata terlaksana dengan baik di SMP Bhakti pertiwi dan semua mata pelajaran terintegrasikan pada program adiwiyata tidak hanya materi fikih saja bahkan ada muatan lokal khusus untuk pembelajaran PLH, yang perlu dipahami posisi adiwiyata yaitu menjaga lingkungan, warga sekolah tidak boleh menggunakan air berlebihan harus hemat air disitu terkait dengan pembelajaran fikih tentang thahara.Berdasakan hasil observasi yang telah dilakukan oleh peneliti, warga sekolah SMP Bhakti pertiwi pada dasarnya telah memiliki karakter peduli lingkungan seperti menjaga kebersihan lingkungan sekolah, setiap hari ada bagian pihak kebersihan yang merawat dan menajaga lingkungan sekolah, warga sekolah SMP Bhakti Pertiwi mayoritas terdiri dari golongan orang

\footnotetext{
${ }^{4}$ Wawancara, Abdul Wahab, Guru PAI SMP Bhati

Pertiwi, 21 November 2018
} 
menengah keatas dalam artian anak orang mampu dan termasuk manja-manja namun untuk membentuk karakter peduli lingkungan, pihak sekolah membiasakan peserta didik menjaga kebersihan dalam ruangan kelas, seperti memberikan kelompok melaksanakan piket kelas sebelum KBM berlangsung dan sesudahnya agar tidak mengganggu saat belajar mengajar, juga membiaskan tidak memakai sepatukedalam kelas hal ini agar menjaga kesucian suasana kelas.Dilihat dari sudut manapun sekolah SMP Bhakti pertiwi sangat asri tidak ada sampah plastik dll yang berserakan dilingkungan sekolah hal ini disebabkan karna dengan adanya program Adiwiyata menyadarkan peserta didik SMP Bhakti Pertiwi agar peduli dengan lingkungan sekitar.

Sesuai dengan yang dikemukakan oleh (Fahmi, 2015) bahwa dalam proses pembelajran menggunakan atau memilih metode yang tepat agar pembelajaran berjalan secara efektif dan efesien. peneliti menemukan beberapa metode yang diterapkan oleh pendidik kepada peserta didik di SMP Bhakti Pertiwi dalam pembelajaran fikih untuk menyesuaikan dan mempermudah pembelajaran diantaranya: metode ceramah, diskusi, tanya jawab dan demonstarsi semua metode tersebut diterapkan dalam pembelajaran materi fikih serta disesuaikan dengan masing-masing bab dan RRP yang sudah dibuat

3. Hambatan dan pemulihan program adiwiyata

Sekolah Adiwiyata adalah sekolah yang dinilai telah barhasil dalam melaksanakan PLH. Capaian akhir program Adiwiyata diharapkan terbentuk sekolah berwawasan lingkungan, sekolah berawawasan lingkungan hidup yaitu sekolah yang menerapkan nilai-nilai cinta pada lingkungan sekolah. Dalam pelaksanaan pendidikan lingkungan hidup SMP Bhakti Pertiwi menjumpai permasalahan yang menghambat pelaksanan program Adiwiyata. Menurut ustad Masrur devisi Adiwiyata mengartikan Adiwiyata sebagai sekolah peduli dan berbudaya lingkungan setiap program jika tidak ada hambatannya kurang menarik, entah itu dari salah satu komponenyang ada dianataranya: Kebijakan Berwawasan Lingkungan, Kurikulum Berwawasan Lingkungan, Kegiatan Lingkungan Berbasis Partisipatif, Pengelolaan Sarana dan Prasarana Ramah Lingkungan. karena Adiwiyata yang diurusi bukan hanya RRP guru akan tetapi melainkan sivitas semua guru dan tidak semua RPP bisa diintegrasikan dengan program Adiwiyata. ${ }^{6}$

Untuk mengatasi hambatan tersebut maka perlu dilakukan 1.kebijakan dari pihak kepala sekolah untuk menerbitkan surat keputusan kepada guru, karyawan, tentang tugas serta tanggung jawab agarkeputusan dapat dilaksanakan secara efektif. 2. Pembentukan kadisiplinan dengan adanya pembentukan ini mendudukung kepentingan strategi untuk meningkatkan kinerja, mengatur aktivitas secara terarah dalam pengawasan.

Hal senada membandingkan dengan peneliti (Mukani, 2017) dalam jurnal yang berjudul "pendidikan karakter peduli lingkungan berbasis Adiwiyata pada mmata pelajaran fikih di MTSN tambakberas jombang" dalam penelitiannya khusus implemenatsi pembelajaran fikih, siswa MTSN tambakberas mayoritas bertempat tinggal di pondok pesantren sehingga tidak hanya diajarkan di sekolah saja akan tetapi dipondok diajarkan lebih mendalam lagi mengenai kitab-kitab yang membahas kehidupan manusia. Pembentukan karakter peduli lingkungan di MTSN tambakberas melalui pembelajaran fikih telah terintegrasi dengan baik.

Sedangkan temuan peneliti saat ini di SMP Bhakti Pertiwi yang berjudul "rancangan pembelajaran fikih dalam kebijakan

\footnotetext{
${ }^{6}$ Wawancara Masrur, Devisi Adiwiyata SMP Bhakti

Pertiwi, 6 Desember 2018
} 
Adiwiyata SMP Bhakti pertiwi" dapat ditemukan oleh peneliti bahwa sekolah SMP Bhakti Pertiwi mengintegrasikan semua mata pelajaran pada Adiwiyata salah satunya mata pelajaran PAI materi fikih, pada dasarnya warga sekolah mempunyai karakter peduli lingkungan dengan baik juga menerapakan cara penggunaan hemat air dan listri, terdapat pula pembelelajaran muatan lokal khusus pembelajaran pendidikan lingkungan hidup (PLH) jadi bagi guru-guru tidak terlalu memfokuskan PLH pada setiap pelajaran hanya saja mengingat untuk peduli terhadap lingkungan.

\section{KESIMPULAN}

SMP Bhakti pertwi telah berhasil meraih Adiwiyata sampai tingkat mandiri, keberhasilan tersebut tidak lepas dari usaha semua warga sekolah, guru, peserta didik dan para staf lainnya. Setiap sekolah yang mempunyai program Adiwiyata harus mengintegrasikan semua mata pelajaran pada PLH, salah satu matapelajaran yang diangkat oleh peniliti yaitu pembelajaran pendidikan agama Islam materi fikih, karena terdapat beberapa isi materi mengenai hubungan manusia dengan alam, hubungan manusia dengan Allah SWT, dan menjelaskan hukum-hukum terkait dengan kehidupan sehari-hari sepertiyang tercantum dalam bab thahara (bersesuci)

Warga sekolah SMP Bhakti Pertiwi mempunyai penanaman karakter peduli lingkungan. Dari hasil penelitian yang berjudul "rancangan pembelajaran dalam konsep Adiwiyata" peneliti menemukan bahwa mata pelajaran fikih yang terintegrasi dengan program Adiwiyata pada SMP Bhakti Pertiwi yaitu peserta didik ditanamkan dan diarahkan untuk hidup bersih menjaga kelestarian lingkungan sekolah, menghemat listrik dan hemat air Artinya program Adiwiyata berjalan dengan sangat baik di SMP Bhakti Pertiwi tidak hanya melalui pembelajaran fikih saja, namun dalam menerapkan pembelajaran PLH semua mata pelajaran terintegrasi bahkan ada pembelajaran khusus yaitu muatan lokah untuk PLH. Juga beberapa metode yang diterapkan oleh pendidik kepada peserta didik di SMP Bhakti Pertiwi dalam pembelajaran fikih untuk menyesuaikan dan mempermudah pembelajaran diantaranya: metode ceramah, diskusi, tanya jawab dan demonstarsi. 
DAFTAR PUSTAKA

Al-anwari, A. M. (2016). Pengembangan Media Ajar Pendidikan Lingkungan Hidup Terintegrasi dengan Ajaran Islam tentang Lingkungan di SDIT AlAzhar Jambi The Development of Life Environmental Education Teaching Media Integrated to Islamic Teaching of the Environment in Al-Azhar Isl. Kontektual, 31(1), 101-120.

Bahrudin, M. D. F. (2017). PELAKSANAAN PROGRAM ADIWIYATA DALAM MENDUKUNG PEMBENTUKAN KARAKTER PEDULI LINGKUNGAN. Pendidikan Geografi, 17, 25-37.

Chusnul, M. (2016). KONSTRUKSI STRATEGI PEMBELAJARAN BERBASIS MULTIPLE INTELLIGENCES SEBAGAI UPAYA PEMECAHAN MASALAH BELAJAR. Pedagogik; Jurnal Pendidikan, 3(2), 1-12.

Fahmi, M. R. (2015). PENGUATAN PENDIDIKAN NILAI DIBIDANG FIQH; STUDI PEMIKIRAN FALAK. ATTURATS, 9, 57-66.

Hasan Baharun, M. (2018). Konstruksi pendidikan karakter di madrasah berbasis pesantren. JURNAL MUDARRISUNA, 8(1), 149-174.

Hasibuan, N. (2016). IMPLEMENTASI
MEDIA

PEMBELAJARAN

DALAM

PENDIDIKAN

AGAMA ISLAM. Darul 'Ilmi, 04(01), 22-39.

Landriany, E. (2014). Implementasi Kebijakan Adiwiyata Dalam Upaya Mewujudkan Pendidikan Lingkungan Hidup di SMA Kota Malang. Kebijakan Dan Pengembangan Pendidikan, 2, 8288.

Lusiana Sri Sunarti1, Isjoni 2, Z. (2017). Pengaruh Implementasi Program Adiwiyata Terhadap Perilaku Warga Sekolah Pada SekolahAdiwiyata Mandiri Di Kota Pekanbaru. Dinamika Lingkungan Indonesia, 4, 139147.

Muhamad Tisna Nugraha. (2016). Pengembangan Model Kurikulum Pendidikan Agama Islam ( PAI ) Menuju Masyarakat Ekonomi Asean ( MEA ). At-Turats, 10(1), 13-21.

Mukani, teto sumarsono. (2017). PENDIDIKAN KARAKTER PEDULI LINGKUNGAN BERBASIS ADIWIYATA PADA MATA PELAJARAN FIQIH DI MTsN TAMBAKBERAS JOMBANG. Jurnal Pendidikan Agama Islam (Journal of Islamic Education Studies), 5, 181-200.

Muttaqin, A. (2017). PELAKSANAAN PROGRAM ADIWIYATA PADA MATA PELAJARAN ALQUR'AN HADITS DI MTSN TAMBAKBERAS JOMBANG. Dinamika, 2(2), 1-26. 
NURHAYANI. (2017). No

TitlePENERAPAN METODE

SIMULASI

DALAM

PEMBELAJARAN FIKIH

IBADAH BAGI SISWA DI MTS

YMPI SEI TUALANG RASO

TANJUNG BALAI

NURHAYANI. Ansiru, 1, 88-104.

Ramdani, R. B. (2006). No

TitleIMPLEMENTASI

PROGRAM ADIWIYATA

DALAM PENGELOLAAN

LINGKUNGAN SEKOLAH DI

SMPN 3 SUKABUM.

Rizky Dewi Iswari*, S. W. U., \& Jurusan. (2017). Evaluasi Penerapan Program Adiwiyata Untuk Membentuk Perilaku Peduli Lingkungan di Kalangan Siswa. Ilmu Lingkungan, 15(1), 35-41. https://doi.org/10.14710/jil.15.1.3 5-41

Siti Maesaroh. (2013). Peranan Metode Pembelajaran Terhadap Minat Dan Prestasi Belajar Pendidikan Agama Islam. Kependidikan, 1(metode pembelajaran), 150 168.

https://doi.org/10.2307/539575

Sutrisno, V., \& Siswanto, B. T. (2016). Faktor-

Faktor Yang Mempengaruhi Hasil Belajar Siswa Pada Pembelajaran Praktik Kelistrikan Otomotif Smk Di Kota Yogyakarta. Jurnal Pendidikan Vokasi, 6(1), 112-119.

Syathori, A. (2013). KURIKULUM 2013 MATA PELAJARAN FIQIH DI MADRASAH TSANAWIYAH (Implementasi,
Analisis dan Pengembangannya). Al-Tarbawi Al-Haditsah: Jurnal Pendidikan Islam, 2(1).

ZA, T. (2017). Sistem pendidikan di indonesia-antara solusi dan ilusi, (July).

https://doi.org/10.13140/RG.2.2.2 1465.62569

Zaenudin. (2015). Meningkatkan Hasil Belajar Siswa pada Mata Pelajaran Fiqh Melalui Penerapan Strategi Bingo A . Pendahuluan Mata Pelajaran Fiqih adalah salah satu mata pelajaran Pendidikan Agama Islam yang diarahkan untuk menyiapkan peserta didik untuk mengenal, memahami. Edukasia: Jurnal Penelitian Pendidikan Islam, 10(2), 301-318. 